\title{
High-intensity acceleration in soccer. Why is the evaluation method important? Aceleraciones de alta intensidad en el fútbol. ¿Por qué es importante el método de evaluación? *Francisco Ignacio Martínez-Cabrera, **Francisco Javier Núñez-Sánchez, ${ }^{* * * A l e j a n d r o ~ M u n ̃ o z-L o ́ p e z, ~}{ }^{* * * M o i s e ́ s ~ d e ~}$ Hoyo \\ *Universidad Isabel I, Burgos (España), **Universidad Pablo de Olavide (España), ***Universidad de Sevilla (España)
}

\begin{abstract}
The aim of the current study was to analyze the possible differences between the use of different kinds of thresholds to assess high-intensity acceleration efforts, both in number and distance covered in young elite soccer players. A total of 26 young soccer players were analyzed during 18 competitive matches $(\mathrm{n}=108)$. High-intensity acceleration efforts were assessed using an individual relative threshold based on the capacity of acceleration from different initial speeds, considering high-intensity acceleration when it was $>75 \%$ of the maximal acceleration $\left(>75 \% \mathrm{a}_{\max }\right.$ ). It was also used a threshold $>21 \mathrm{~km} \cdot \mathrm{h}^{-1}$ when the acceleration intensity was $>75 \% \mathrm{a}_{\max }$, and absolute thresholds of $>3 \mathrm{~m} \cdot \mathrm{s}^{-2}$ and $>4 \mathrm{~m} \cdot \mathrm{s}^{-2}$, both in number and distance (meters). Post hoc analysis showed pairwise significant differences between the use of high-intensity thresholds $(\mathrm{p}<.05)$, in number and distance. The results showed that the use of absolute thresholds could overestimate $\left(>3 \mathrm{~m} \cdot \mathrm{s}^{-2}\right)$ and underestimate $\left(>4 \mathrm{~m} \cdot \mathrm{s}^{-2}\right.$ and $\left.>21 \mathrm{~km} \cdot \mathrm{h}^{-1}\right)$ high-intensity acceleration efforts (both in number and distance $)$ in comparison with the use of an individual relative threshold $(\mathrm{p}<.05)$, whereas a threshold based on high-speed running could underestimate high-intensity acceleration efforts $(\mathrm{p}<.05)$. Therefore we conclude that the use of absolute acceleration thresholds $\left(>3 \mathrm{~m} \cdot \mathrm{s}^{-2}\right.$ and $>4 \mathrm{~m} \cdot \mathrm{s}^{-2}$ ) may not be appropriate to analyze these efforts in young soccer players. In addition, speed running thresholds could underestimate high-intensity actions developed in short distance, being more appropriate to combine with an individual relative threshold to assess high-intensity action in soccer matches.
\end{abstract}

Keywords: acceleration; high intensity; soccer.

Resumen. El objetivo del presente estudio fue analizar las posibles diferencias entre el uso de diferentes tipos de umbrales para evaluar los esfuerzos de alta intensidad, tanto en número como en distancia recorrida en jóvenes futbolistas de élite. Un total de 26 jóvenes jugadores fueron analizados durante 18 partidos oficiales $(n=108)$. Los esfuerzos de alta intensidad se evaluaron utilizando un umbral relativo individualizado basado en la capacidad de acelerar a diferentes velocidades iniciales, considerando la aceleración de alta intensidad cuando fue $>75 \%$ de la capacidad máxima de acelerar $\left(>75 \% \mathrm{a}_{\max }\right)$. Se utilizó también un umbral $>21 \mathrm{~km} \cdot \mathrm{h}^{-1}$ cuando la intensidad de la aceleración fue $>75 \% \mathrm{a}_{\max }, \mathrm{y}$ umbrales absolutos $>3 \mathrm{~m} \cdot \mathrm{s}^{-2} \mathrm{y}>4 \mathrm{~m} \cdot \mathrm{s}^{-2}$, contabilizando tanto el número como la distancia (metros). El análisis post hoc mostró diferencias significativas por pares entre el uso de umbrales a alta intensidad $(\mathrm{p}<.05)$, en número y distancia. Los resultados mostraron que el uso de umbrales absolutos podría sobreestimar $\left(>3 \mathrm{~m} \cdot \mathrm{s}^{-2}\right)$ y subestimar $\left(>4 \mathrm{~m} \cdot \mathrm{s}^{-2} \mathrm{y}>21 \mathrm{~km} \cdot \mathrm{h}^{-1}\right)$ esfuerzos de aceleración a alta intensidad (tanto en número como en distancia) en comparación con el uso de un umbral relativo individualizado $(\mathrm{p}<.05)$. Por lo tanto, concluimos que el uso de umbrales de aceleración absolutos $\left(>3 \mathrm{~m} \cdot \mathrm{s}^{-2} \mathrm{y}>4 \mathrm{~m} \cdot \mathrm{s}^{-2}\right)$ puede no ser apropiado para analizar estos esfuerzos de alta intensidad en jóvenes futbolistas. Además, los umbrales de velocidad de carrera podrían subestimar las acciones de alta intensidad desarrolladas en una distancia corta, siendo más apropiados combinarlos con un umbral relativo individual para evaluar las acciones de alta intensidad en partidos de fútbol.

Palabras clave: aceleración; alta intensidad; fútbol.

\section{Introduction}

In recent decades, there has been increasing interest in recent decades in the analysis of time-motion of the physical demands in soccer, which has become an essential tool for the assessment of physical effort, both in matches and training (Bradley, Di Mascio, Peart, Olsen, \& Sheldon, 2010; De Hoyo, Sañudo, Suárez-Arrones, Carrasco, Joel, Domínguez-Cobo, \& Núñez-Sánchez, 2018; Di Salvo, Gregson, Atkinson, Tordoff, \& Drust, 2009). In this sense, the study of high-intensity actions has focused the interest of many authors, since these actions are essential to match results because the vast majority of determining actions occur at high intensity, such as reaching a ball earlier or moving away from an opponent, score a goal or avoid it (Buchheit, Haddad, Simson, Palazzi, Bourdon, Di Salvo, \& MéndezVillanueva, 2014; Carling, Bloomfield, Nelsen, \& Reilly, 2008; Di Salvo et al., 2009). In addition, this type of actions have a high relevance in the probability of injury, since many of the incidents that occur in soccer happen at high running speed

Fecha recepción: 22-07-20. Fecha de aceptación: 02-10-20 Francisco Ignacio Martínez-Cabrera fimarcab@outlook.com or during accelerations or decelerations, being recommended a specific work in this kind of actions to try to reduce the likelihood of injury (Carling, Gall, \& Reilly, 2010; Le Gall, Carling, Reilly, Church, \& Rochcongar, 2006).

In line with these arguments, high-intensity actions in soccer have been popularly assessed using speed running thresholds between 18 and $30 \mathrm{~km} \cdot \mathrm{h}^{-1}$ (De Hoyo et al., 2018). However, this approach, based on absolute thresholds, have important limitations that should be considered, such as not taking into account high-intensity actions that are developed in a short place or distance, where high-speed running is not achieved (Osgnach, Poser, Bernardini, Rinaldo, \& Di Prampero, 2010). Therefore, absolute high-speed running categories could underestimate efforts in movements with high-intensity accelerations (Akenhead, Hayes, Thompson, \& French, 2013; Osgnach et al., 2010; Portas, Harley, Barnes, \& Rush, 2010). According to this, Varley \& Aughey (2013) found that just $15 \%$ of acceleration $\left(>2.78 \mathrm{~m} \cdot \mathrm{s}^{-2}\right)$ reaches a final speed $>15 \mathrm{~km} \cdot \mathrm{h}^{-1}$, which means that $85 \%$ of the accelerations that could be considered as high-intensity would not be detected if we used a thresholds based on running speed. Then, we would be excluding a large amount of high-intensity effort in our analysis. To avoid this misinterpretation, a specific acceleration analysis is 
necessary. In addition, it is known that accelerations demand more energy than running at constant speed (Osgnach et al., 2010)

Until now, the vast majority of studies that include acceleration demands have used absolute thresholds to assess high-intensity accelerations such as $>2 \mathrm{~m} \cdot \mathrm{s}^{-2}$ (Stevens, de Ruiter, Twesk, Savalsbergh, \& Beek, 2017), >2.78 $\mathrm{m} \cdot \mathrm{s}^{-2}$ (Varley \& Aughey, 2013), >3 $\mathrm{m} \cdot \mathrm{s}^{-2}$ (Akenhead et al., 2013; Osgnach et al., 2010), or even $>4 \mathrm{~m} \cdot \mathrm{s}^{-2}$ (Bradley et al., 2010). However, the use of these absolute thresholds has some limitations that should be taken into account. Firstly, they could underestimate or overestimate the intensity of the acceleration because they do not consider the individual capacity of each player (Jastrzebsky \& Radziminski, 2015). Secondly, they do not consider that the capacity to accelerate is greater when the acceleration begins from a standing position compared with low- or high-speed running (Bradley et al., 2010; Sonderegger, Tschoop, \& Taube; 2016). Recently, Sonderegger et al. (2016) designed a new model to assess the acceleration demands using the percentage of the maximal acceleration $\left(\mathrm{a}_{\max }\right)$ based on a linear regression model, attending to the individual capacity of acceleration from different initial speeds $\left(\mathrm{S}_{\text {init }}\right)$. Furthermore, this proposal allows us to analyse in each action the magnitude of the acceleration carried out as a function of the $\mathrm{S}_{\text {init }}$ prior to acceleration. This approach has already been used to assess high-intensity acceleration efforts in professional soccer players (De Hoyo et al., 2018) and in young soccer players (Martínez-Cabrera, Núñez-Sánchez, Losada, Otero-Esquina, Sánchez, \& De Hoyo, 2018), concluding that this model could be more accurate in assessing high-acceleration efforts in soccer than the traditional approach using absolute thresholds.

In consequence, the choice of the valuation methods to measure movement demands in soccer has great importance in avoiding the misinterpretation (underestimating or overestimating) of efforts by soccer players in high-intensity actions. This would help us to know more accurately what the physical demands of soccer matches are, and enable more effective and efficient training strategies to be designed. Therefore, the aim of this study was to analyze the possible differences between the use of different kinds of thresholds to assess high-intensity acceleration efforts in terms of number and distance covered. We hypothesized that the number of high-intensity accelerations would be different as a function of using an individual relative threshold according to the $\mathrm{S}_{\text {init }}$ prior to acceleration, being overestimated or underestimated by absolute thresholds in number and distance. In addition, we believed that using an individual relative threshold to assess the number and the distance covered at high-intensity acceleration will report differences with the number and the distance of high-intensity accelerations that reached in the final sprint speed $\left(>21 \mathrm{~km} \cdot \mathrm{h}^{-}\right.$ $\left.{ }^{1}\right)$ and with the use of both absolute thresholds, being the difference greater in the highest absolute threshold used $(>4$ $\left.\mathrm{m} \cdot \mathrm{s}^{-2}\right)$

\section{Methods}

\section{Subjects}

Twenty-six young soccer players (mean $\pm \mathrm{SD}$; age $17.3 \pm$
1.1 years; height $175.6 \pm 5.8 \mathrm{~cm}$; and mass $72.4 \pm 5.2 \mathrm{~kg}$ ) from an elite professional Spanish soccer club (La Liga BBVA) were assessed during their competitive club-level matches. All players participated on average in $\mathrm{H} » 15$ hours of combined soccer (4"5 sessions), strength training (1 or 2 sessions), individual specific training (1 session), and competitive play ( 1 or 2 games) per week. The data of the matches were obtained from routine monitoring of physical demands during official games. All procedures performed were in accordance with the Declaration of Helsinki and with a Local Ethical Committee. Players were informed about the aims, experimental protocol, procedures, risks and benefits of the study prior to any data collection. All soccer players signed an informed consent and, in the case of those under the age of 18 , this was signed by their parents.

\section{Experimental approach to the problem}

High-intensity acceleration efforts were assessed in number and distance using an approach from Sonderegger et al. (2016), which considers the $\mathrm{S}_{\text {init }}$ prior to the acceleration and the individual capacity of acceleration from different $\mathrm{S}_{\text {init }}$ of each soccer player. This approach included a test with 4 maximal voluntary accelerations $\left(\mathrm{a}_{\max }\right)$ (over $40 \mathrm{~m}$ ) starting from a different running speed. An individual relative threshold according to their personal a $a_{\max }$ from different $\mathrm{S}_{\text {init }}$ (using an individual regression model) ( $\tilde{\mathrm{A}} 75 \%$ of the $\mathrm{a}_{\max }$ ) and absolute thresholds ( $\tilde{\mathrm{A}} 3 \mathrm{~m} \cdot \mathrm{s}^{-2}$ and $>4 \mathrm{~m} \cdot \mathrm{s}^{-2}$ ) were used to assess the high-intensity acceleration efforts (number and distance) during soccer matches. To know more about the possible lack of information in the evaluation of highintensity actions in soccer depending on the type of threshold employed (speed or acceleration), we have also included a threshold $>21 \mathrm{~km} \cdot \mathrm{h}^{-1}$ (Casamichana, Castellano, \& Castagna, 2012) when the intensity of the acceleration was Ã $75 \%$ of the $\mathrm{a}_{\max }$. All threshold models were also compared.

\section{Procedures}

Data were collected from 18 matches and a total of 108 individual match files were analyzed $(\mathrm{n}=108)$, excluding data from goalkeepers and players who were injured or in the rehabilitation process. Only full matches were analyzed, excluding those who were substituted. Tactically, only matches where 1-4-2-3-1 formation was used were included. All players undertook four maximally accelerated sprints over $40 \mathrm{~m}$ to achieve maximal speed running, (Buchheit, Simpson, Peltola, \& Mendez-Villanueva, 2012; Méndez-Villanueva, Buchheit, Simpson, Peltola, \& Bourdon, 2011) based on the proposal of Sonderegger et al. (2016) to relativize the acceleration actions in the function of $\mathrm{S}_{\text {init }}$ and maximal acceleration to set an individual threshold in function of the capacity to accelerate of each soccer players from different $\mathrm{S}_{\text {init }}$.

Before the test, a standard 20 min warm-up was performed before the familiarization exercises and test (Sonderegger et al., 2016), in February, and players were familiarized with the execution of the test on the same artificial turf in the previous two weeks. The first sprint was performed from a standing position, whereas the others were performed from three different constants: $6 \mathrm{~km} \cdot \mathrm{h}^{-1} ; 10.8 \mathrm{~km} \cdot \mathrm{h}^{-1}$; and $15 \mathrm{~km} \cdot \mathrm{h}^{-1}$. A recovery time of 3 minutes was given between each sprint. 
To target $\mathrm{S}_{\text {init }}$, short auditory signals were given through a speaker placed in the middle of the pitch to cover the distance between 5-meter markers. The players maintained the target running speed for $25 " 40$ meters, and at an arbitrary time point, the paced runner blew a whistle, which signaled players to accelerate maximally and to run as fast as possible. Then, an individual regression model was used for each player to measure the relationship between $\mathrm{S}_{\text {init }}$ and maximum acceleration performed of each player based on the test data. During accelerations to a given $\mathrm{S}_{\text {init }}$ in the test, as the $\mathrm{S}_{\text {init }}$ were different among players, for a greater precision of the individual regression model, the $\mathrm{S}_{\text {init }}$ used for the equation was the real $\mathrm{S}_{\text {init }}$ performed instead of the $\mathrm{S}_{\text {init }}$ established (Sonderegger et al., 2016).

\section{Data collection and match analysis measures}

Physical performance in matches was assessed using portable global positioning system (GPS) technology units, sampling at $15 \mathrm{~Hz}$ (SPI Pro X, GPSports, Canberra, Australia). To allow the acquisition of satellite signals, all devices were activated before warming up (more than 20 minutes before kick-off) (Duffield, Reid, Baker, \& Spratford, 2010). The GPS device was held in place by a padded neoprene vest, positioned at the upper thoracic spine. The validity and reliability of this model was assessed regarding the distance covered, different running speeds and soccer-specific activities, providing more reliable measurements of the demands of movements than 1 or $5 \mathrm{~Hz}$ GPS (Johnston, Watsford, Kelly, Pine, \& Spurrs, 2014; Portas et al., 2010; Varley, Fairweather, \& Aughey, 2012; Waldrom, Worsfold, Twist, \& Lamb, 2011).

The percentage of acceleration was calculated according to Sonderegger et al. (percentage acceleration $[\%]=\mathrm{a}_{\text {max action }}$ $\left./ \mathrm{a}_{\max } * 100\right)$ (Sonderegger et al., 2016). To ensure the individual assessment of each player, we used the individual regression model equation of each player as a function of the test for the subsequent match analysis. To analyze the acceleration, all actions with highpercentage accelerations ( $\tilde{A} 75 \%$ of the $\mathrm{a}_{\max }$ ) were collected in number and distance (De Hoyo et al., 2018; Martínez-Cabrera et al., 2018; Sonderegger et al., 2016). In addition, the number and distance of high accelerations were also collected in actions that are performed $\tilde{A} 75 \%$ of the $\mathrm{a}_{\text {max }}$ and reach a final speed $>21 \mathrm{~km} \cdot \mathrm{h}^{-1}$. To compare between the individual threshold for the function of the $\mathrm{S}_{\text {init }}$ and the absolute thresholds, the number and the distance of high accelerations $\tilde{\mathrm{A}} 3 \mathrm{~m} \cdot \mathrm{s}^{-2}$ and $\tilde{\mathrm{A}} 4 \mathrm{~m} \cdot \mathrm{s}$ ${ }^{2}$ were also collected (Akenhead et al., 2013; the mean $\mathrm{SD}$.

Table 1.
Bradley et al., 2010; Dwyer \& Gabbet, 2012; Johnston et al., 2014; Osgnach et al., 2010) All data were downloaded from the GPSport software Team AMS (Canberra, Australia). Later, the relative thresholds were calculated using a custom Microsoft Excel spreadsheet with minimum speed and maximal acceleration $\left(\mathrm{m} \cdot \mathrm{s}^{-2}\right)$ data from the software.

\section{Statistical Analysis}

Data is shown as mean \pm standard error $(95 \%$ confidence intervals-CI). A generalized linear mixed-model analysis of variance was used to examine the differences between the assessing methods used to classify the players' accelerations (fixed factor). Subject ID was used as a random effect and each match and player position was used as a covariable. Model was fit to a Gamma probability distribution and log was used as link function. Post hoc analysis was used via Bonferroni adjustment. Tests were performed using SPSS v.22 for Windows (IBM SPSS Statistics, Illinois, USA). The significance level was set at $\mathrm{p}<.05$.

\section{Results}

There were significant differences between the assessing methods used to classify the players' high-acceleration efforts in both number of accelerations $\left(\mathrm{F}_{413,3}=1433.63, \mathrm{p}<.001\right)$ and distance covered $\left(\mathrm{F}_{413,3}=460.52, \mathrm{p}<.001\right)$. Figure 1 shows the boxplots for each variable. The number of accelerations for each calculation method was: $>3 \mathrm{~m} \cdot \mathrm{s}^{-2}=26.71 \pm 1.93(23.18$ $-30.7995 \% \mathrm{CI}) ;>4 \mathrm{~m} \cdot \mathrm{s}^{-2}=3.42 \pm 0.26(2.94-3.8995 \% \mathrm{CI})$; $>75 \%-\mathrm{a}_{\max }=20.77 \pm 1.55(17.94-24.0595 \% \mathrm{CI})$; and $>75 \%$ $\mathrm{a}_{\max } \&>21 \mathrm{~km} \cdot \mathrm{h}^{-1}=8.29 \pm 0.77(6.91-9.9495 \% \mathrm{CI})$. The distance covered for each method was: $>3 \mathrm{~m} \cdot \mathrm{s}^{-2}=385.82 \pm$ $38.23(317.53-468.8095 \% \mathrm{CI}) ;>4 \mathrm{~m} \cdot \mathrm{s}^{-2}=55.15 \pm 6.14(44.30$
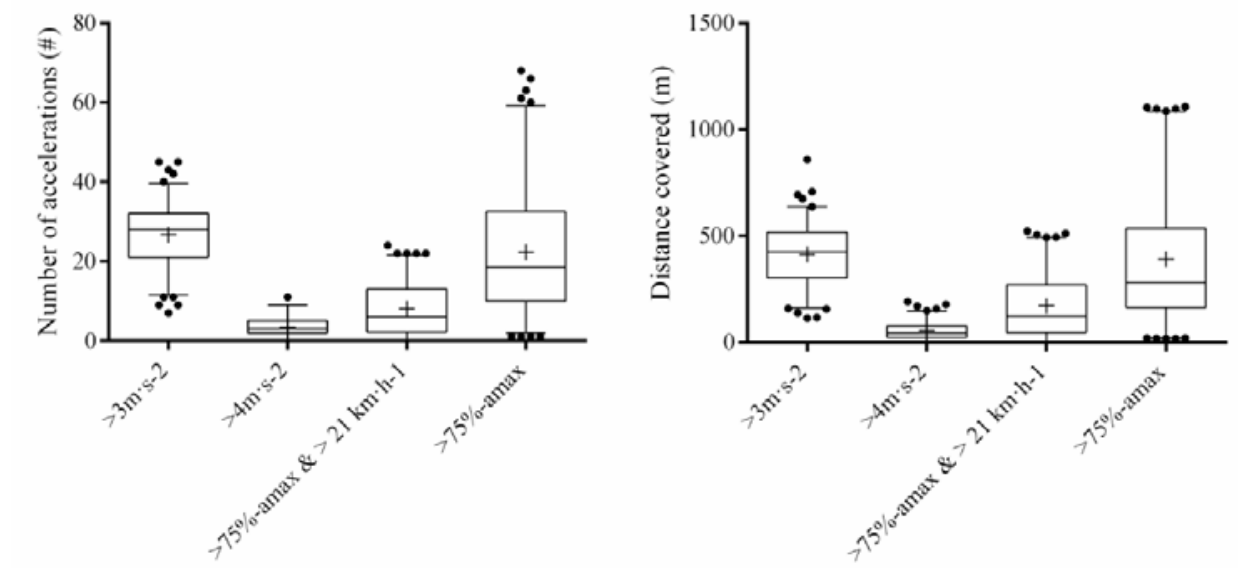

Figure 1. Number and distance of high-acceleration efforts using different thresholds. Data are

Statistical post hoc analysis between methods of assessing high high-intensity effort

\begin{tabular}{|c|c|c|c|c|c|c|}
\hline & \multirow{2}{*}{$\begin{array}{c}\text { Mean } \\
\text { Differences }\end{array}$} & \multirow{2}{*}{$\begin{array}{c}\text { Standard } \\
\text { error }\end{array}$} & \multirow{2}{*}{$\begin{array}{c}\text { Adjusted } \\
\text { Significance }\end{array}$} & \multicolumn{2}{|c|}{ Confidence Interval (95\%) } \\
\hline & & & & & Lower Bound & Upper Bound \\
\hline \multirow{6}{*}{$\begin{array}{l}\text { Number of high } \\
\text { accelerations }\end{array}$} & $>75 \% \mathrm{a}_{\max }$ vs $>3 \mathrm{~m} \cdot \mathrm{s}^{-2}$ & 5.94 & 0.75 & .000 & 4.48 & 7.41 \\
\hline & $>75 \% \mathrm{a}_{\max }$ vs $>4 \mathrm{~m} \cdot \mathrm{s}^{-2}$ & 17.35 & 1.32 & .000 & 14.76 & 19.94 \\
\hline & $>75 \% \mathrm{a}_{\max } \mathrm{vs}>75 \% \mathrm{a}_{\max }$ and $>21 \mathrm{~km} \cdot \mathrm{h}^{-1}$ & 12.48 & 1.13 & .000 & 10.27 & 14.69 \\
\hline & $>3 \mathrm{~m} \cdot \mathrm{s}^{-2} \mathrm{vs}>4 \mathrm{~m} \cdot \mathrm{s}^{-2}$ & 23.29 & 1.70 & .000 & 19.95 & 26.63 \\
\hline & $>3 \mathrm{~m} \cdot \mathrm{s}^{-2}$ vs $>75 \% \mathrm{a}_{\max }$ and $>21 \mathrm{~km} \cdot \mathrm{h}^{-1}$ & 18.42 & 1.46 & .000 & 15.56 & 21.29 \\
\hline & $>4 \mathrm{~m} \cdot \mathrm{s}^{-2}$ vs $>75 \% \mathrm{a}$ max and $>21 \mathrm{~km} \cdot \mathrm{h}^{-1}$ & 4.87 & 0.61 & .000 & 3.66 & 6.07 \\
\hline \multirow{6}{*}{$\begin{array}{l}\text { Distance at high- } \\
\text { intensity } \\
\text { acceleration } \\
\text { (m) }\end{array}$} & $>75 \% \mathrm{a}_{\max } \mathrm{vs}>3 \mathrm{~m} \cdot \mathrm{s}^{-2}$ & 47.01 & 15.20 & .002 & 17.13 & 76.89 \\
\hline & $>75 \% \mathrm{a}_{\max } \mathrm{vs}>4 \mathrm{~m} \cdot \mathrm{s}^{-2}$ & 283.66 & 30.84 & .000 & 206.29 & 361.04 \\
\hline & $>75 \% \mathrm{a}_{\max }$ vs $>75 \% \mathrm{a}_{\max }$ and $>21 \mathrm{~km} \cdot \mathrm{h}^{-1}$ & 181.67 & 24.20 & .000 & 123.51 & 239.83 \\
\hline & $>3 \mathrm{~m} \cdot \mathrm{s}^{-2} \mathrm{vs}>4 \mathrm{~m} \cdot \mathrm{s}^{-2}$ & 330.67 & 33.04 & .000 & 243.09 & 418.26 \\
\hline & $>3 \mathrm{~m} \cdot \mathrm{s}^{-2} \mathrm{vs}>75 \% \mathrm{a}_{\max }$ and $>21 \mathrm{~km} \cdot \mathrm{h}^{-1}$ & 228.68 & 25.17 & .000 & 163.54 & 293.83 \\
\hline & $>4 \mathrm{~m} \cdot \mathrm{s}^{-2}$ vs $>75 \% \mathrm{a}_{\max }$ and $>21 \mathrm{~km} \cdot \mathrm{h}^{-1}$ & 101.99 & 14.39 & .000 & 69.63 & 134.36 \\
\hline
\end{tabular}


$68.6595 \% \mathrm{CI}) ;>75 \%-\mathrm{a}_{\max }=338.81 \pm 35.65(275.49-416.68$ $95 \% \mathrm{CI})$; and $>75 \% \mathrm{a}_{\max } \&>21 \mathrm{~km} \cdot \mathrm{h}^{-1}=157.14 \pm 18.31(124.96$ $-197.6095 \% \mathrm{CI})$.

Post hoc analysis showed pairwise significant differences between all calculation methods at $\mathrm{p}<.005$ (table 1 ). The greatest differences were found between the calculation method $>3 \mathrm{~m} \cdot \mathrm{s}^{-2}$ and $>4 \mathrm{~m} \cdot \mathrm{s}^{-2}$ in both number of accelerations $(23.29 \pm 1.70, \mathrm{p}<.001,19.95-26.6295 \% \mathrm{CI})$ and distance covered $(330.67 \pm 33.04 \mathrm{~m}, \mathrm{p}<.001,243.08-418.26 \mathrm{~m} 95 \% \mathrm{CI})$. The lower differences were found between the calculation methods $>3 \mathrm{~m} \cdot \mathrm{s}^{-2}$ and $>75 \%-\mathrm{a}_{\max }$ in both number of accelerations $(5.94 \pm 0.74, \mathrm{p}<.001,4.48-7.4195 \% \mathrm{CI})$ and distance covered $(47.01 \pm 15.20 \mathrm{~m}, \mathrm{p}=.002,17.13-76.88 \mathrm{~m}$ $95 \% \mathrm{CI})$.

\section{Discussion}

Throughout the literature it can be observed how different types of thresholds have been used to assess high-intensity acceleration efforts in soccer players. However, some of them have some limitations that should be considered. The main aim of this study was to analyze the possible differences between the use of different kinds of thresholds to assess high-intensity acceleration efforts in number and distance. The results showed that the use of absolutes thresholds $(>3$ $\mathrm{m} \cdot \mathrm{s}^{-2}$ and $>4 \mathrm{~m} \cdot \mathrm{s}^{-2}$ ) and the use of speed thresholds that includes a high-intensity acceleration to assess high-intensity actions in soccer matches in young soccer players could over- and underestimate high-intensity acceleration efforts (both in number and distance) in comparison with the use of an individual relative threshold according to the individual capacity to accelerate of each player from different $\mathrm{S}_{\text {init }}$

With regard to the number of accelerations $>75 \% \mathrm{a}_{\max }$, our results showed that the high-intensity acceleration efforts were overestimated when an absolute threshold $>3$ $\mathrm{m} \cdot \mathrm{s}^{-2}$ was used, both in number and distance $(\mathrm{p}<.05)$. In this way, recent studies have showed that the use of an absolute threshold to assess acceleration demands could over- or underestimate the number of accelerations because it does not consider the $\mathrm{S}_{\text {init }}$ prior to acceleration and does not consider the individual capacity of each player (MartínezCabrera et al., 2018; Sonderegger et al., 2016). The cause of these findings could be that the vast majority of accelerations in soccer are started from standing or walking in comparison to medium or high-speed running (Bradley et al., 2010; Martínez-Cabrera et al., 2018; Varley \& Aughey, 2013). In this context, the possibility of maximal voluntary acceleration is higher from standing or walking than from high $\mathrm{S}_{\text {init }}$ running (Sonderegger et al., 2016). So, whether most acceleration efforts begin from standing or walking, the absolute capacity to accelerate is higher than from a higher speed running, which means that it is possible to achieve the absolute thresholds more easily than from a higher speed running, even though the individual relative magnitude of effort is not high $\left(>75 \% \mathrm{a}_{\mathrm{max}}\right)$. This could be why the results of acceleration efforts have been higher (number and distance) using a threshold $>3 \mathrm{~m} \cdot \mathrm{s}^{-2}$ than using an individual relative threshold, which considers the maximum capacity to accelerate from different $\mathrm{S}_{\text {init }}$. Although the absolute magnitude of acceleration is «considerably» high, the real magnitude of effort for soccer players according to their maximum acceleration capacities is not. This findings could make us indicate that the assessments that we make through the use of this absolute threshold may not be showing the real effort made by soccer players. Therefore, we can draw the wrong conclusions from the effort made.

Attending to the use of an absolute acceleration threshold $>4 \mathrm{~m} \cdot \mathrm{s}^{-2}$, data indicated that it significantly underestimated the number and distance of high-intensity accelerations in comparison with the relative threshold. In the same way, the distance accelerating at high intensity was underestimated by $300 \mathrm{~m}$ approximately $(\mathrm{p}<.05)$. According to these results, Mendez-Villanueva et al. (2011) found differences in the capacity to accelerate as a function of age and biological maturity. In line with these arguments, several authors have used the threshold of $>4 \mathrm{~m} \cdot \mathrm{s}^{-2}$ to assess highintensity acceleration in senior soccer players (Bradley et al., 2010; Wehbe, Hartwing, \& Duncan, 2014). However, according to our results this seems to be extremely high for U19 soccer players, which means that its use underestimates high-intensity acceleration efforts in number and distance. Therefore, its use would not be recommendable for this age group.

Speed running thresholds have been commonly used in time»motion analysis to assess high-intensity demands during matches or trainings (Buchheit et al., 2010; Carling et al., 2008; Di Salvo et al., 2009). However, they could fall into the error of not consider high-intensity actions that have been developed in a short distance or time because highspeed running is not achieved, even if the player is accelerating as fast as he/she can (Osgnach et al., 2010). In this context, our results showed that the number of highintensity actions $>75 \% \mathrm{a}_{\max }$ is substantially higher than the number of accelerations of those characteristics that reach a final speed $>21 \mathrm{~km} \cdot \mathrm{h}^{-1}$. This means that there are a lot of high-intensity activities that may not be assessed if just the speed running approach is used to analyze the movement demands. The same occurs with the distance covered, which could be underestimated substantially (50\% less, approximately) if just high-speed thresholds are used to assess high-intensity efforts during young soccer matches $(\mathrm{p}<.05)$. That means that, looking at the results found by Buchheit, Mendez-Villanueva, Simpson, \& Bourdon (2010), young soccer players U18 covered $\sim 666 \mathrm{~m}$ sprinting $(>19.1$ $\mathrm{km} \cdot \mathrm{h}^{-1}$ ). Comparing this with our results, it could mean an underestimation of $\sim 23 \%$ when just speed running thresholds are used in the assessment of high-intensity efforts, excluding the use of an individual relative threshold to assess acceleration efforts. These differences could be explained because analysis of speed running categories (only) does not take into account the acceleration efforts when a final high-speed running is not achieved. However, in soccer matches, $85 \%$ of accelerations $\left(>2.78 \mathrm{~m} \cdot \mathrm{s}^{-2}\right)$ had a final speed $<15 \mathrm{~km} \cdot \mathrm{h}^{-1}$ (Varley \& Aughey, 2013). Therefore, all these acceleration actions are not considered as an important effort for the player, being classified as a medium or low intensity activity, which is an error. In our case, using an individual relative threshold according to the capacity to accelerate from different $\mathrm{S}_{\text {init }}$, the percentage of high-intensity accelerations that reached a final speed $>21 \mathrm{~km} \cdot \mathrm{h}^{-1}$ were $40 \%$ 
in the number of high accelerations and about $46 \%$ of the difference in the distance accelerating at high intensity $(>75 \%$ $\left.\mathrm{a}_{\max }\right)$. In line with these arguments, the use of both methods ([speed threshold and individual relative threshold of acceleration (Sonderegger's proposal)]) seems to be the best way to assess high-intensity acceleration efforts in young soccer matches, avoiding the misinterpretation of highintensity actions.

Our study had some limitations that should be considered. Firstly, the individual threshold used with each player was a function of an initial test. However, the maximum capacity of acceleration could change over the season because of the training and/or the process of the biological maturation process. In addition, the results may be conditioned by the performance at the specific moment of the test. Then, we do not know exactly the specific performance level of the players at other moment of the season. Another limitation could be that, for practical reasons, it was not possible to assess other teams in the same category, it only being possible to register the same squad throughout the season. Finally, the differences between the physical demands in young soccer players and professional soccer players and females are already known, which could mean that the results could vary according to the group analyzed.

\section{Conclusions}

The high-intensity actions analysis in soccer offers important support for the design of strategies to improve the physical performance in soccer and reduce the risk of injury. Therefore, the methods of quantification of these actions is very important in order to avoid a misinterpretation of the real demands, which could lead to errors in the design of specific training programs. The use of an individual threshold relative to the maximal capacity to accelerate as a function of the $\mathrm{S}_{\text {init }}$ offers important support to the assessment of acceleration in soccer, which is essential for the development of training programs designed to improve physical performance and reduce the risk of injury. Our results showed that the use of absolute thresholds to assess high-acceleration efforts such as $>3 \mathrm{~m} \cdot \mathrm{s}^{-2}$ or $>4 \mathrm{~m} \cdot \mathrm{s}^{-2}$ should be taken into account because they could over- or underestimate (respectively) the real effort in young soccer players. In addition, if just the method based on high-speed running thresholds is used, high-intensity efforts in activities which involve acceleration could be considerably underestimated in number and distance when an individualized threshold relative to the maximum capacity to accelerate is not also included in the analysis. Therefore, it would be recommended to include high-speed running and acceleration (Sonderegger's proposal) thresholds in the assessment of high-intensity efforts in young soccer players. If it is not possible to use an individual relative threshold to assess high-acceleration efforts due to practical reasons, the thresholds $>3 \mathrm{~m} \cdot \mathrm{s}^{-2}$ would be more appropriate than the threshold $>4 \mathrm{~m} \cdot \mathrm{s}^{-2}$ for young soccer players.

\section{Disclosure statement}

The authors certify that there is no conflict of interest with any financial organization regarding the material discussed in the manuscript.

\section{References}

Akenhead, R., Hayes, P., Thompson, K., \& French, D. (2013). Diminutions of acceleration and deceleration output during professional football match play. Journal of Science and Medicine in Sport, 16(6), 556"561.

Bradley, P.S., Di Mascio, M., Peart, D., Olsen, P., \& Sheldon, B. (2010). High-intensity activity profiles of elite soccer players at different performance levels. Journal of Strength and Conditioning Research, 24(9), 2343"2351.

Buchheit, M., Al Haddad, H., Simpson, B., Palazzi,D., Bourdon, P., Di Salvo, V., \& Méndez-Villanueva, A. (2014). Monitoring acceleration with GPS in football: time to slow down? International Journal of Sports Physiology and Performance, 9(3), 442-445.

Buchheit, M., Mendez-Villanueva,A., Simpson, B.M., \& Bourdon, P. (2010). Match running performance and fitness in youth soccer. International Journal of Sports Medicine, 31(11), 818"825.

Buchheit, M., Simpson, B.M., Peltola, E., \& Mendez-Villanueva, A. (2012). Assessing maximal sprinting speed in highly trained young soccer players. International Journal of Sports Physiology and Performance, 7(1), 76"78.

Carling, C., Bloomfield, J., Nelsen, L., \& Reilly, T. (2008). The role of motion analysis in elite soccer, contemporary performance measurement techniques and work rate data. Sports Medicine, 38(10), 839"862

Carling, C., Gall, F., \& Reilly, T. (2005). Effects of physical efforts on injury in elite soccer. International Journal of Sports Medicine, 31(3), 180-185.

Casamichana, D., Castellano, J., \& Castagna, C. (2012). Comparing the physical demands of friendly matches and small-sided games in semi-professional soccer players. Journal of Strength and Conditioning Research, 26(3), 837"843.

De Hoyo, M., Sañudo, B., Suárez-Arrones, L., Carrasco, L., Joel, T., DomínguezCobo, S., \& Núñez-Sánchez, F. (2018). Analysis of the acceleration profile according to initial speed and positional role in elite professional male soccer players. Journal of Sports Medicine and Physical Fitness, 58(12), 1774"1780.

Di Salvo, V., Gregson, W., Atkinson, G., Tordoff, P., \& Drust, B. (2009). Analysis of high intensity activity in Premier League soccer. International Journal of Sports Medicine, 30(3), 205"212.

Duffield, R., Reid, M., Baker, J., \& Spratford, W. (2010). Accuracy and reliability of GPS devices for measurement of movement patterns in confined spaces for courtbased sports. Journal of Science and Medicine in Sport, 13(5), 523"525.

Dwyer, D., \& Gabbet, T. (2012). Global positioning system data analysis: velocity ranges and a new definition of sprinting for field sport athletes. Journal of Strength and Conditioning Research, 26(3), 818"824.

Jastrzebski, Z., \& Radziminski, L. (2015). Individual vs general time-motion analysis and physiological response in 4vs4 and $5 \mathrm{vs} 5$ small-sided soccer games. International Journal of Performance Analysis in Sport, 15(1), 397"341.

Johnston, R., Watsford, M., Kelly, S., Pine, R., \& Spurs, R. (2014). The validity and reliability of $10 \mathrm{~Hz}$ and $15 \mathrm{~Hz}$ GPS units for assessing athlete movement demands. Journal of Strength and Conditioning Research, 28(6), 1649-1655.

Le Gall, F., Carling, C., Reilly, T., Church, J., \& Rochcongar, P. (2006). Incidence of injuries in elite French youth soccer players: a 10-season report. The American Journal of Sports Medicine, 34(6), 928-938.

Martinez-Cabrera, F.I., Núñez-Sánchez, F.J., Losada, J., Otero-Esquina, C., Sánchez, H., \& de Hoyo, M. (2018). Use of individual relative thresholds to assess acceleration in young soccer players according to initial speed. Journal of Strength and Conditioning Research, ahead of print.

Mendez-Villanueva, A., Buchheit, M., Simpson, B., Peltola, E., \& Bourdon, P. (2011). Does on-field sprinting performance in young soccer players depend on how fast they can run or how fast they do run? Journal of Strength and Conditioning Research, 25(9), 2634"2638.

Osgnach, C., Poser, S., Bernardini, R., Rinaldo, R., \& di Prampero, P. (2010) Energy cost and metabolic power in elite soccer: a new match analysis approach. Medicine \& Science in Sports \& Exercise, 42(1), 170"178.

Portas, M., Harley, J., Barnes, C., \& Rush, C. (2010). The validity and reliability of $1 \mathrm{~Hz}$ and $5 \mathrm{~Hz}$ global positioning system for lineal, multidirectional, and soccerspecific activities. International Journal of Sports Physiology and Performance, 5(4) 448"458.

Sonderegger, K., Tschoop, M., \& Taube, W. (2016). The challenge of evaluating the intensity of short actions in soccer: a new methodological approach using percentage acceleration. PloS One, 11(11).

Stevens, T., de Ruiter, C., Twisk, J., Savalsbergh, G., \& Beek, P. (2017). Quantification of in-season training load relative to match load in professional Dutch Eredivisie football players. Science and Medicine in Football, 1(2), 117"125.

Varley, M., \& Aughey, R. (2013). Acceleration profiles in elite Australian soccer. International Journal of Sports Medicine, 34(1), 34"39.

Varley, M., Fairweather, I., \& Aughey, R. (2012). Validity and reliability of GPS for measuring instantaneous velocity during acceleration, deceleration, and constant motion. Journal of Sports Science, 30(2), 121"127.

Waldron, M., Worsfold, P., Twist, C., \& Lamb, K. (2011). Concurrent validity and test-retest reliability of a global positioning system (GPS) and timing gate to assess sprint performance variables. Journal of Sports Science, 29(15), $1613 " 1619$.

Wehbe, G., Hartwig, T., \& Duncan, C. (2014). Movement analysis of Australian national league soccer players using global positioning system technology. Journal of Strength and Conditioning Research, 28(3), 834"842. 